Investigations of the electronic data interchange practice:

Comparative study of companies operating in the automotive sector in Morocco

Jardini, Bahija $\square$

ENSA, Ibn Zohr University, Agadir, Morocco (Bahija.jardini@gmail.com)

Amri, Mostapha

ENCG, Hassan II University, Casablanca, Morocco (amrimostapha@yahoo.fr)

El Kyal, Malika

ENSA, Ibn Zohr University, Agadir, Morocco (m.elkyal@uiz.ac.ma)

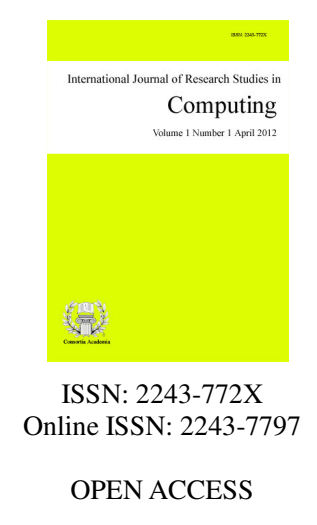

Received: 29 March 2016

Revised: 2 July 2016

DOI: $10.5861 /$ ijrsc. 2016.1499

Accepted: 18 July 2016

Available Online: 18 August 2016

\title{
Abstract
}

The evolution of technology and the structural changes in the global economy had led the organizations to recreate their value chain and to allocate more resources to information system. The companies wishing to integrate distribution networks into their logistic system are turning to the EDI (the Electronic Data Interchange) which can extend the management of their physical value chain till the point of consumption of their product. The EDI provides a concordance between the physical flow and the information flow to enable the supply chain management to be effective and fast. This technology allow illustrating the role of Information Technology in the Supply Chain: without information system, the global supply chain cannot be efficient. Furthermore, Morocco is the first automaker in North Africa and the second in the African continent. This country is now recognized as industrial platform for the production and export in the automotive industry. This Morocco's position on the global value chain led us to conduct this study which aims to explore the practice of EDI in the automotive sector and its impact on the supply chain management.

Keywords: EDI; information flow; SCM; Morocco; automotive sector 


\section{Investigations of the electronic data interchange practice: Comparative study of companies operating in the automotive sector in Morocco}

\section{Introduction}

Today, the optimal adjustment of computer technology on the strategies of organizations is the condition of the success and competitiveness of businesses that must cope with the complexities of the integration of these new tools in their management systems. In fact, to accompany the structural changes in the world economy, new policies closely related technologies have emerged. But for that they are a factor of sustainable competitive advantages, the organization should be able to master the use and to delineate the location constraints.

In the automotive industry, the organization of firms in networks and the internationalization of trade, are forcing the operators in the sector to have the information reliable, useful, accurate, complete and relevant, and to make it available and usable by all partners in real time. Because of this, and for an efficient management of the Supply Chain, manufacturers, OEMS and automotive distributor shall ensure to optimize the flow of information which is apprehended in the same way as the physical flow (Vallin, 2003). Among the technologies which ensure the optimization of these flows in the supply chain, we will cite the Electronic Data Interchange (EDI) which allows the synchronization between the physical flows and the flow of information by a better sharing of data and thus ensures the improvement of Supply Chain Management.

EDI offers an alternative to traditional means of communication concerning the transfer of documents such as purchase orders, invoices, shipping notices, and many others (Vijayasarathy \& Tyler, 1997). These structured data can be processed by the information systems on computer without any human intervention is not necessary. As well, the data transmitted by the system of emission can be retrieved directly and interpreted by the receiving system (June et al., 2000). Aid by its globalization, the automotive industry committed manufacturers to integrate their suppliers as quickly as possible, regardless of the country in which they are located: in Eastern Europe, Morocco, Brazil or China. It is therefore essential that the suppliers based in these regions can exchange EDI documents as simply as possible. The ICT skills on the emerging markets or to lower cost are generally limited, car manufacturers must ensure that they can provide the tools EDI easy to use, which allow even more small suppliers to trade and communicate by electronic means.

This research purpose is to propose elements of answers to the following problem: "How the EDI (Electronic Data Interchange) is it practical in the automotive sector in Morocco and how does it impact on the Supply Chain Management?" The choice of the Moroccan automobile industry has been motivated by the increased importance that won of the sector more and more. First automaker in North Africa and the second continent, Morocco is now recognized as industrial platform for the production and export in the sector, the figures also claim, between January and July 2014, the exports of the Moroccan automotive industry have reached 11.76 billion against MDH 6.1 billion MDH on the same period in 2013, thus exceeding, the phosphate sector, which class the automotive industry first contributor to exports of the Kingdom (Jardini et al., 2015). This sector with strong potential promises also colossal investments in the years to come; it aroused the greed of major German manufacturers, Asian and even Americans.

This article is intended to render account of the relation existing between the information technology (IT) and the management of logistics flows; it is the result of a literature review and a several case studies of exploratory Electronic Data Interchange (EDI) in the automotive sector in Morocco. The semi-structured interviews conducted with the professionals of the automotive sector (industrial, sub-contractors, importers, dealers, etc.) had for objective to put the light, on the one hand, on the reality of the practice of Electronic Data Interchange (EDI) used as a tool to optimize the flow of logistical information with all the benefits and, on the other hand, on the limits and the implications of the non-adoption of this technology for some operators (Jardini 
et al., 2015).

\section{The Automotive Supply Chain automotive}

\subsection{Concept of Supply Chain Management}

The concept of the supply chain is a relatively new concept, a twenty year, (Pimor \& Fender, 2008); it is the result of an evolution at several levels: both at the level of systems of information, modes of transport, computer networks (Courtois et al., 2010). For a better understanding, it would be wise to operate a historical reminder to make the point in the evolution of methods and tools in the field of industrial management and logistics. The supply chain can be, also, defined as the overall process of client satisfaction by the creation of a value chain that integrates optimally all the actors to the origin of the realization of a product or family of products (Courtois et al., 2010).

For the supply chain management (SCM), the Council of Supply Chain Management Professionals association (North American) has defined as follows: "the SCM is the planning and the management of all activities falling under the search for suppliers, of the supply, processing and all the activities of the logistics management. It also includes the coordination and the cooperation with the partners in the chain which can be suppliers, intermediaries, logistics service providers and customers. In essence, the SCM integrates the management of the supply and demand within and between the companies" (CSCMP, 2007).

Pache and Paraponaris, (2006) assimilated the SCM to a network enterprise, Fabbe-Costes (2005) referred to as synonymous with the business transactions or the enterprise modular, the only difference between these types is located at the level of stability or non-members, the organizational characteristics will be, by contrast, generally identical. The SCM can be discussed under the vision of the processes, under that of the networks or still under the skills development. The process approach is among others that of the Global Supply Chain Forum (TAG) resumed between other by Frankel et al. (2008) and Mentzer et al. (2008) and of the method Supply Chain Operations Reference (SCOR). The network approach allows studying the shape of the various types of coordination or the various configurations of the relationship between the different partners of the supply chain.

\subsection{The structure of the Automotive Supply Chain}

The Supply Chain Management (SCM) of the automotive industry is structured in a segmented manner. Upstream of builders and manufacturers, are the providers category 1. As a general rule, these companies provide the main components or sub-systems of vehicles, such as the suspension or the gearbox. Then, downstream, we find the suppliers category 2 that usually offer components to suppliers category 1 , for example pumps, electric motors or bearings. Then, even more downstream, we find the suppliers of category 3 which provide to suppliers category 2 of components ranging from media, to the seals in passing by the components for the machines, and many others.

As the providers' category 1 is the most important for the car manufacturers, they are generally located in close proximity to their factories in order to facilitate the process of production in tight flow. The suppliers' category 2 could be located anywhere in the world and the businesses in this industry are many to have installed their production sites in a country with low labor costs, for example in China or India. In addition to these categories, there are also the suppliers of raw materials, including steel, who deliver their products directly to automobile manufacturers. Downstream manufacturers exist for the logistics providers' third party (3PL) who carries the finished vehicles toward the sites of storage and the hubs of distribution throughout the world. These vehicles are then shipped to the dealer networks in a timely manner. 


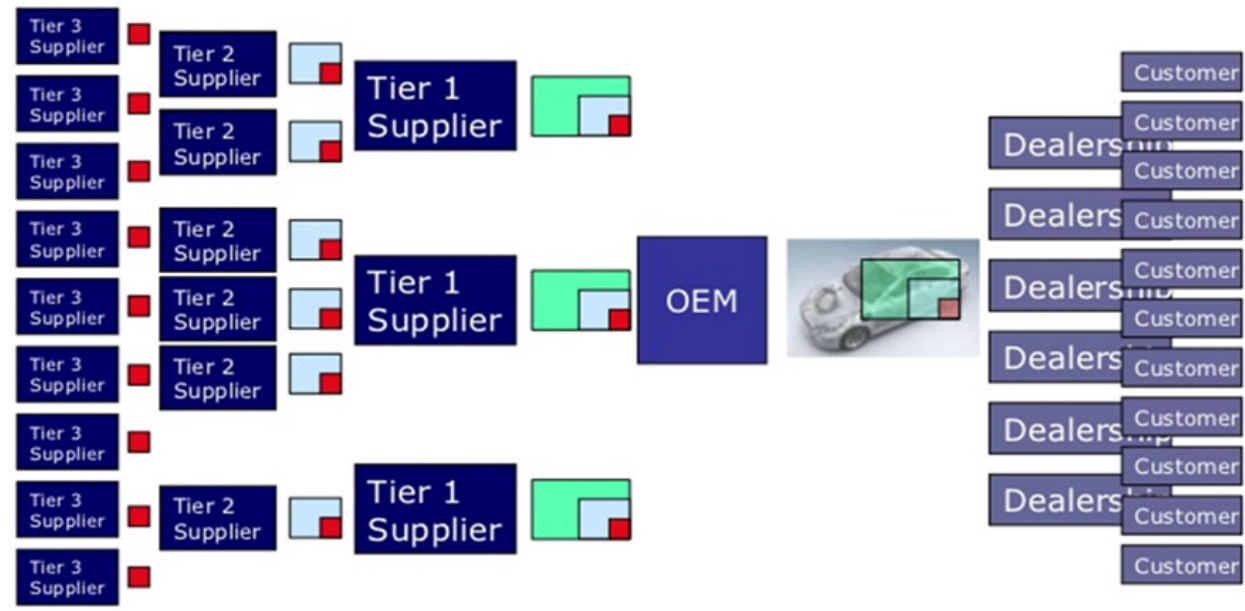

Figure 1. Automotive supply chain

\section{Electronic Data Interchange: Technical modalities and applications}

\subsection{Origin and benefits of the of EDI (Electronic Data Interchange)}

Used for the first time in the United States during the 1960s (Roesch, 1991), the EDI technology is defined as a transfer from computer to computer, from one application to another, of structured data according to the predetermined messages and standardized via a means of telecommunication. This technique allows the automatic exchange of data coded according to a language previously agreed between the applications and the systems of heterogeneous information. The exchanges are made by using various telecommunications networks (June et al., 2000). Even if EDI is used in internal communication, its main applications are intended to facilitate the collaboration between organizations such as the company, its suppliers, its customers, carriers, and many others (Court, 2004).

The EDI offers an alternative to traditional means of communication concerning the transfer of documents such as purchase orders, invoices, shipping notices, and many others (Vijayasarathy \& Tyler, 1997). These structured data can be processed by the information systems on computer without any human intervention is not necessary. As well, the data transmitted by the system of emission can be retrieved directly and interpreted by the receiving system (June et al., 2000).

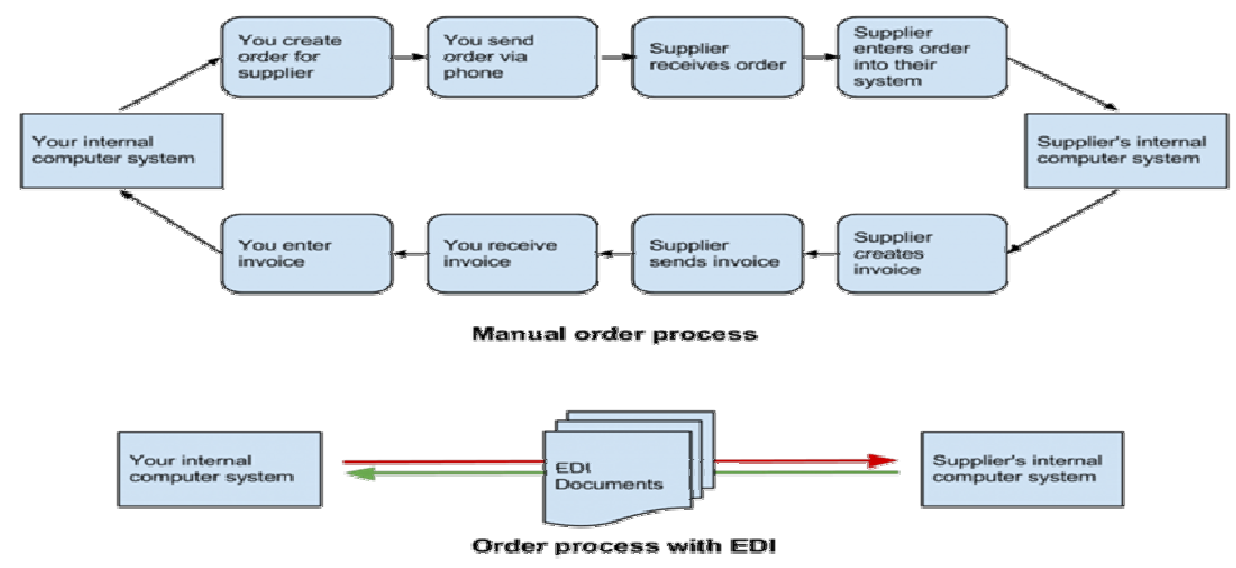

Figure 2. Manual order process and order process with EDI 
Although the use of EDI has many advantages (Lim \& Palvia, 2001), the reasons for its adoption are various and seem to have an impact on its use. Different typologies of reasons for the adoption of EDI can be found in the literature (Vijayasarathy \& Tyler, 1997).The satisfaction of the customer seems to be the main reason, in fact, an important customer often requires the adoption of EDI to its partners "small" (Court, 2004).

The EDI logistics can also be defined as the establishment between businesses and to the interior of undertakings or groups participating in a Supply Chain, of scenarios of standardized operations and transfers of information using protocols, languages, telecommunications standards or of bar codes, etc., to achieve, monitor and control of transfers of goods with all their accompanying technical (transportation and handling), commercial and financial by performing whenever possible data transfers of computers to computers. The development of EDI is the culmination of the progress of information technology, telecommunications and also very many efforts of normalizations: examples include the digitization of telecommunications, the development of value-added networks (VAN) or of the internet with their protocols, languages, and standards of telecommunications or the reading of bar codes.

Then, the EDI allows the synchronization between the physical flows and the flow of information in supply chain (Jardini, El Kyal, \& Amri, 2016). In effect, when the products are in the process of shipment to the customer, the latter emits a stream of information with all the commands that correspond to the physical goods. This allows a concordance between the physical and the information in order to be effective, competent and fast in the Supply Chain Management. This new technology allows illustrating the role of it in the Supply Chain: without information system, the global supply chain cannot be efficient. With the implementation of appropriate solutions, EDI offers many opportunities to facilitate the management and improve productivity. In addition, this system allows you to integrate a stream of ongoing communications between the suppliers, service providers and clients. Finally, it unifies all the electronic communications under a single application and ensures the sending and receipt of electronic messages through a single connection point.

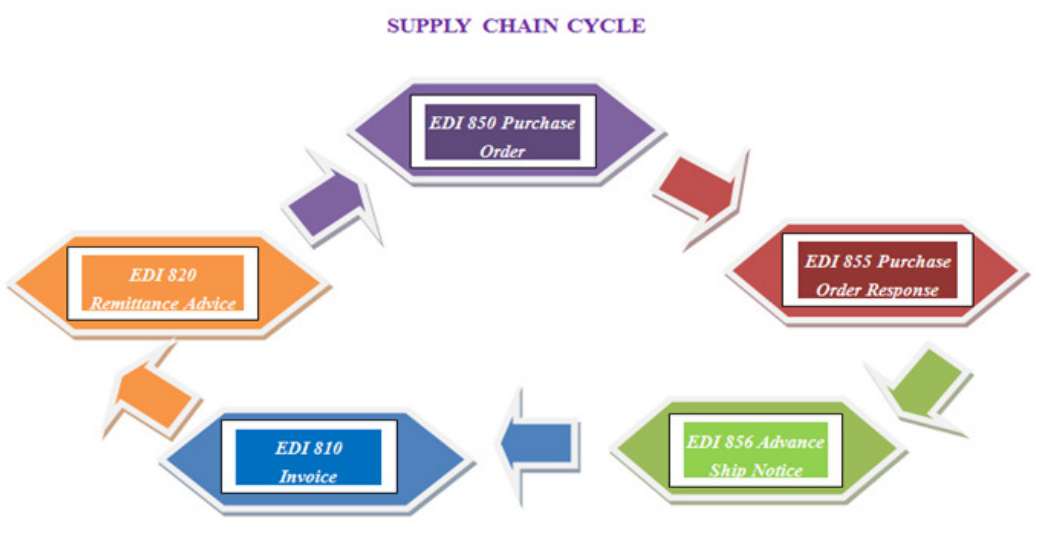

Figure 3. EDI in Supply chain cycle (personal elaboration)

\subsection{Standards of documents used}

In addition to the standards more traditional such as ANSI X12 and EDIFACT, several regional standards are used by car manufacturers in Europe. For example, in France, the standard ODETTE is widely used by manufacturers such as PSA and, in Germany, the body VDA has developed a series of standards for documents which are specifically adapted to BMW, Daimler AG and VW group. The use of Web EDI solutions is common in this industry since they allow the smaller trading partners to exchange business documents with the builders. To discourage these constructors to create Web portals EDI each with an aspect and a felt different, Odette has introduced, in Europe, a standard stipulating how the Web forms Edi must be presented on an Internet page. Odette 2 is the standard currently in force and the providers of Web EDI solutions must, as a general rule, be certified before that their solution is certified by the organization Odette. 
Jardini, B., Amri, M., \& El Kyal, M.

\section{Table 1}

Examples of documents exchanged by EDIFACT

\begin{tabular}{ll}
\hline DELINS & Scheduled Delivery \\
EXHAND & Management of exceptions of the delivery schedule \\
CALDEL & Delivery in tight flow \\
SYNCRO & Phased Delivery \\
FORDIS & Ready for dispatch \\
AVIEXP & Notice of shipment \\
INVOIC & Invoice \\
STOACT & Inventory Report \\
TRINAD & Routing Instructions \\
CONSUM & Grouping \\
ORDERR & Purchase order \\
ORDCHG & Change of Command \\
FOR REPORT & Response to the command \\
PRILST & Tariff List \\
REMADV & Payment slip \\
STATAC & Statement of Account \\
\hline
\end{tabular}

\subsection{Communication Protocols}

The automotive industry uses various communication protocols such as FTP, but in Europe and therefore the Morocco, the main communication protocol currently used is the OFTP (Odette File Transfer Protocol). THE OFTP is used by the European automobile industry since half of 1980 and the car manufacturers' use, in the majority, this protocol to communicate with their trading partners. With the advent of the Internet, many car manufacturers are collaborating with the organization Odette in order to attempt to adapt the standard OFTP to new practices and a new version called OFTP v2.0 has been placing on the automotive market in 2010. This new version has been designed from the outset for use on the Internet. It allows an exchange of documents in any safety thanks to an encryption process and the exchange of digital certificates. OFTP2 also allows the exchange, in all simplicity, to files of computer aided design (CAD). This exchange is an issue common to the entire automotive industry because of the confidential nature of the transferred files and their large size.

\section{The EDI in the Moroccan automotive Supply Chain}

\subsection{New International Context of automotive sector}

In recent decades, a significant redesign of the value chain has greatly affected the global automotive sector. Accompanied by a reversal in demand and supply to global emerging markets, this new redesign was to cause a major shift in production capacity between the main geographical areas in favor of emerging countries with a share Asia, which rose from 36\% to 52\% between 2003 and 2013 and to a lesser extent South America (3\% to $5 \%$ ) against a decline in the share of developed economies: $33 \%$ to $23 \%$ in Europe and $24 \%$ to $15 \%$ for North America. Another aspect that characterized the industry in recent years is the powerful Asian emerging contracted by demographic and economic powers (China, India), with an average annual growth of $10 \%$, followed by South America (9\% year) and Africa (5\%), against a fall in demand in developed countries with $2 \%$ per year for Europe and $-1 \%$ per year for North America. This new order of demand has pushed manufacturers to explore new locations in countries with a competitive global offer (proximity to major markets, offering logistics, skilled labor...), to better adapt to particular stresses new emerging markets (Jardini, Amri, \& El Kyal, 2016). 


\subsection{Moroccan Automotive industry}

The Moroccan automobile industry consolidates its position in the global value chain of the automobile as confirmed significant achievements made over recent years with an automobile production exceeding 227,570 vehicles in 2014 against only 18546 vehicles in 2003. Morocco became the second vehicle producer in Africa after South Africa with a market share of 35\% in 2014 against 5\% in 2003 and should be further strengthened with the entry into service of the second tranche of the project Renault bringing its total capacity to 340,000 vehicles. The sector exports also surpassed the 40 billion MDH in 2014 showing, as the position of the number one export activities. The Renault plant in Tangier, also celebrated May 5, 2015, the output of the production line of its 400,000 vehicle since the launch of its operations in February 2012. This positioning of Morocco on the global value chain erected the real sector Morocco World Occupation, around which a whole effort was made to support a regular and attractive car offers based on efficient logistics around the harbor Tanger-Med, a range of targeted training, industrial infrastructure dedicated and aids installation.

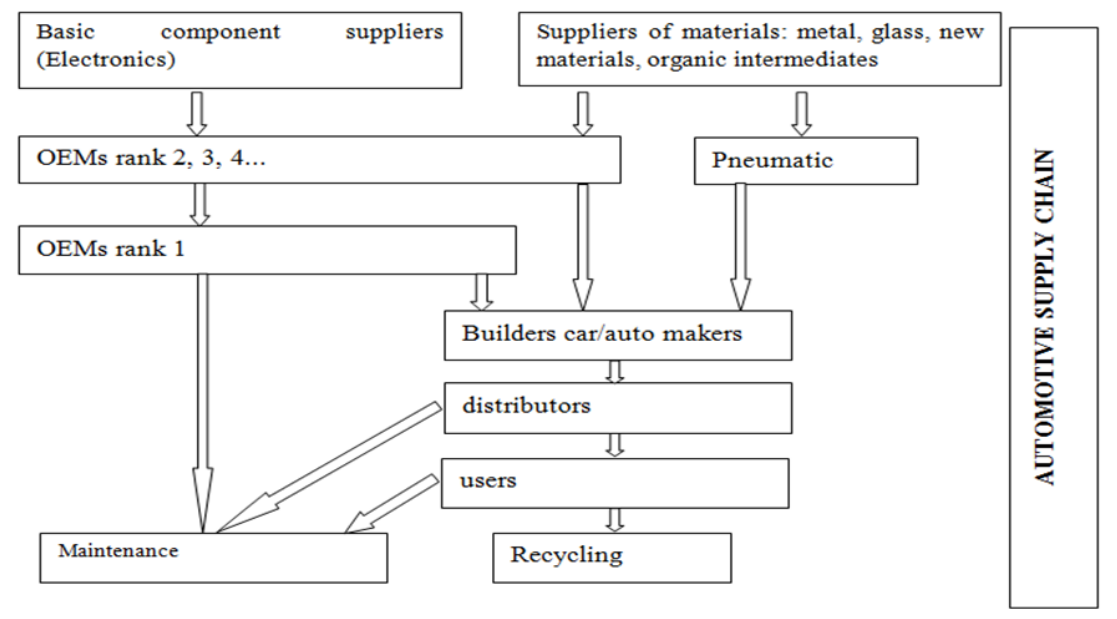

Figure 4. Cartography of the local integration of the automotive industry in Morocco since 1963 to 2016

First automaker in North Africa and the second continent, Morocco is now recognized as industrial platform for the production and export in the sector (Jardini et al., 2015). If Morocco has been able to achieve such off in the car, it is primarily through the Structural many assets specifically provide it:

$>\quad$ Its institutional stability, political and macroeconomic;

$>\quad$ The opening-up of the various free trade agreements with the countries of the partners;

$>\quad$ The structural reforms to improve the business climate that have allowed Morocco to take a leap of 43 places in five years in the Doing Business ranking, from 130th place in 2009 to 87 th in 2014;

$>\quad$ The massive efforts in the port and industrial overhead road infrastructures that allow rapid movement of people, goods flow and data.

The rise of the Moroccan automotive industry is also the fruit of the vision laid out for the sector and particularly attractive offer of value developed. This offer is based on:

$>\quad$ the establishment of a quality infrastructure home with 2 integrated industrial platforms dedicated and benefiting from free zone status: Tangier Automotive City and Kenitra Automotive City

$>\quad$ An innovative and pragmatic training strategy adapted to the needs of the sector: 3 training institutes for careers in the automotive industry (IFMIA) have been set up.

$>\quad$ The contribution of the state to the installation and the acquisition of equipment through the Hassan II 
Fund for Economic and Social Development in order to reduce the cost of the initial investment (30\% of the construction professional costs, limited to $180 \mathrm{EUR} / \mathrm{m}^{2}, 15 \%$ of the costs of equipment for investment in machinery, Cross's contribution to $15 \%$ of the investment amount, capped at 30 million $\mathrm{MDH})$.

All these advantages had the effect of making Morocco a visible automobile platform and attractive to industry leaders. The sector has indeed distinguished in the region and in the continent by the world renowned groups' implantation with their Renault-Nissan head whose activity in Morocco constitutes a development of the automobile engine.

\section{The methodology of the study}

We have chosen to interview various stakeholders in the automotive industry to the upstream and downstream at the, we have therefore been able to exchange with the responsible relationships with suppliers and the Deputy Director of the department of Mount an assembly plant and bodywork, with the Logistics Director of an exclusive importer of French brands and the Director of a subcontractor automobile. Then we wanted to know if the EDI is practice downstream of the SCM of the automobile, we have therefore visited a branch and three dealers dealing with different parent companies, the semi-structured interviews conducted with officials have allowed us to compare the standards and methods of management of different automotive manufacturers and the relations they have with the distributors. An analysis of the content of the interviews allowed us to disclose, on the one hand, the reality of the practice of the Electronic Data Interchange (EDI) used as a tool to optimize the flow of logistical information with all the benefits and the limits of the introduction of this technology in some businesses.

\subsection{Assembly Plant}

This assembly plant for cars of French trade mark practice EDI with all its suppliers who are suppliers in rank 1, the latter must respond to a specification of load which is presented in the form of manual summarizing all the criteria that the supplier must meet before you begin to work with this plant. Among these criteria, a chapter is reserved to the EDI and the web EDI which explicitly clear that the supplier must use EDI in its commercial transactions with the plant (Jardini, El Kyal, \& Amri, 2016). As well, before any exchange, the supplier must sign with the company a "contract inter-exchange EDI", then, it must obtain an approval EDI to its system of information. The EDI homologation process for suppliers is presented by the following chart:

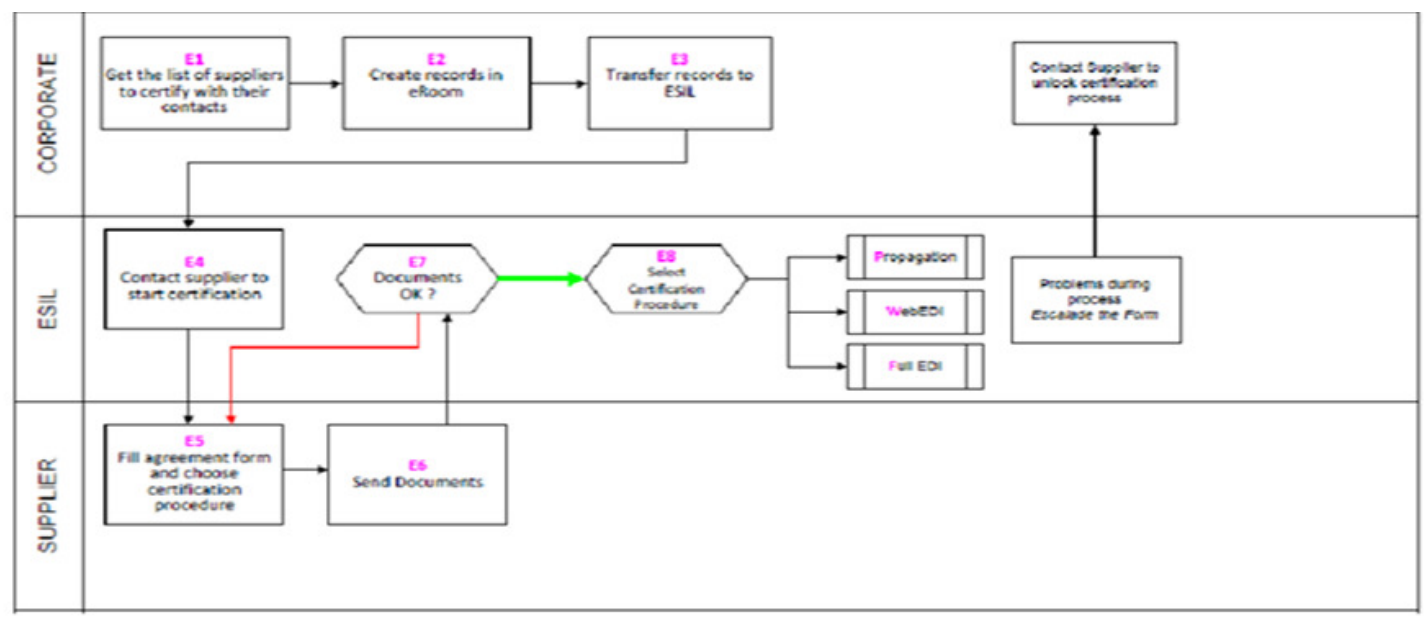

Figure 5. EDI homologation process

The EDI of this manufacturer has for vocation to be global for all industrial entities of the company and for the whole of the panel corresponding supplier, whatever the country concerned that it is in Europe, in Africa or 
in Asia. In fact, the EDI uses by the assembly plant is defined by the parent company in France, it is based on the standards and the international standards recommended by GALIA, the standard used is the international multi-sectoral standard EDIFACT.

\subsection{Importer of French brands}

The logistics manager of the company explained the operation of the information system of the enterprise that allows the management of the flow of information and physical flows for lengthy operations (monitoring of controls, exchange and delivery, invoices, and many others). This company has delegated the transport and management of warehouses of its lots of vehicles to a provider of services installed in the vicinity who supports the preparation of fact sheets of the recipients and the delivery schedule and thus the exchange of data of the company. The platform EDI is hosted on the internet and allows this importer to have a window on the information system of the automobile manufacturer (the features are very limited: monitoring of commands for example). The system used is the VPN S400. In addition, the logistics manager has confirmed that the ERP used by the company is efficient and self-reliant and integrates all the data exchanged with the partners and thus meets the needs of the company management, which provides a system of information reliable and powerful.

\subsection{Subcontractor automotive wiring}

The company is a subcontractor international sis at Kenitra whose mother house is in Turkey; its creation was induced by the inauguration of the plant Renault-Nissan Tangier Med the February 9, 2012 and by the introduction of new equipment manufacturers in automotive cabling in Kenitra and to the Free Zone Tangier. The company operates an approval with companies from wiring and has commercial transactions with all the companies doing the automotive cabling (any brand confused). The exchange of business documents with its partners who are located in Morocco and Turkey is done by internet: the purchase orders and invoice are sent or received by mail. The EDI technology is not known by the company and therefore is not adopted in commercial transactions with partners. The company has an internet connection but do not of intranet network; its staff is composed of 18 employees trained in majority to the Office of the Vocational Training.

\subsection{Car Dealer of French trade mark}

The dealer has confirmed the use of EDI tools that allow him to be in permanent contact with the principal supplier (importer). The tool used was imposed and implemented by the provider and all business transactions with this supplier pass through this network: the staff using the tool has access only has a few features that are in relation with the nature of their responsibilities (control of cars or ordering of spare parts, and many others). The system used is the VPN S400. The manager, by contrast, has the hand to be able to access all types of information and perform any operation needed for its activity. The officials say that this way is effective and completely secure because any document sent or received constitutes a means of evidence and forced the sender or recipient to respect the commitments (command, quantity, delay, and many others).

\subsection{Dealer of luxury cars}

This dealer has explained that the exchange with the primary supplier is done by mail (90\%) more than the reminder by phone. The invoices and shipping notice are sent with the products (cars). In fact, given the volume of trade, which is very low (luxury cars which sell occasionally), the permanent contact with the partner is not required and the level of exchange of documents remains limited. In addition, the company is currently evaluating the installation of computer software allowing him in the future to manage all trades with the various partners.

\subsection{Branch of an Indian manufacturer}

This branch which has 7 years of existence has a system of management and organization very classic. For 
its relations with the mother house located in Casablanca, the orders are placed by fax or by a simple phone call. For the invoices, the boss moves in person in Agadir and resets directly to customers. The mother house by against has the EDI tools allowing him to securely exchange and reliability all exchange with its supplier-manufacturer in India.

\subsection{Car Dealer of German brand}

The manager of the concession has clearly explained the process of data exchange between the dealer and the importer in Casablanca and between the importer and the mother house in Spain. In fact, the importer on Casablanca uses international software which allows you to follow on the system the production chain of cars: bodywork, fitting, painter, and the like. The exchange with the manufacturer and the monitoring of controls is therefore done by EDI without the intervention of any paper document. In fact, everything is visible on the system since the beginning of production up to sending in a boat with all the dates indicating the departure, arrival etc. This system is used by all importers of the mark. The Spanish manufacturer ensures the follow-up of diagnostics and in any time, it can have access to any information.

For the dealer to Agadir, the exchange of information is done in general by mail, sometimes by fax, but at the moment there is not an EDI system installed even if the need is felt to scan the exchange and the project is in the process of reflection. The commands of the spare parts are past two times per month and the delivery is always ensured after 25 days of the order. The commercial also has the possibility to book the cars, on a computerized system centralized, if a customer has already expressed its interest in the purchase or has given a promise to purchase, this booking is viewable by all other commercial which must take into account before responding to a request of customers on a brand, a model, a color or other, the access of commercial remains, however, limited to this option of booking.

\section{Synthesis and discussion of results}

According to the interviews conducted with the automotive industry and the distributors in Morocco, we note that upstream of the chain, the large companies operating in automotive industry practice EDI in their relations with the suppliers rank 1 and the parent company in France, in Spain, in India or other and have an ERP to integrate all the exchanges of a computerized way to optimize the information flows and gain performance, efficiency, and speed. The subcontractor automotive dealership with the OEMS wiring has affirmed the non-use of EDI and the adoption of the common tools of trade of trade documents. Downstream, the distributors have confirmed their need to have the tools that standardize the exchanges and help to avoid losses of time and errors, but a single dealer uses this technology which was imposed by the main supplier. The other dealers continue to use the conventional tools of trade, such as the fax, the phone, the mail, sometimes moving a responsible if imposed in case of need.

The EDI technology is really not very widespread throughout the automotive logistics chain especially for SMES whose capabilities are very limited at the hardware level, at the level of human skills and technological knowledge. In addition, the need for monitoring of controls and of spare parts of computerized manner is not very pressing for some. Therefore, this technology is not in the service of the end distributors who do not use even if it offers different potentialities and it is for this reason that new tools are in a course of study for the standardize for SMES automobiles as is the case of the European project Auto-integration intended to improve the practices automotive EDI. Auto-integration provided to SMES whose human and physical capacity, and even technological are restricted, a solution that is easy and inexpensive to exchange their information flow in dematerialized relying on the Internet and its technologies, publishers of ERP and the exchange platforms B2B. Currently, Self-integration is during the test to ensure the transition to a digital channel unified, it is intended particularly to SMES in the automotive industry and it has for objective to integrate them into the Supply Chain digital. 


\subsection{Implications and conclusion}

Operates for forty years, the Electronic Data Interchange allows companies to transmit information in an automated way: commands, shipping notices, invoices, and orders for transportation. The advantage of the device implements before the reduction of the costs, the optimization of processing of data and the reliability of trade with this ambition: $5+1$ zeros: 0 Paper, 0 error, 0 time, 0 Stock, 0 Cost, 0 Neuron. In the automotive industry, manufacturers are committed to integrate their suppliers as quickly as possible, regardless of the country in which they are located. It is therefore essential that the suppliers based in different regions, even the smaller ones, can exchange EDI documents as simply as possible.

In Morocco, while digital is more and more present in the commercial scale, industrial and societal, the businesses are impacted by the massive introduction of new technologies in the professional life. But, it has been noticed a very large discrepancy between the operators interviewed. The large companies wear out of EDI which is usually imposed by the manufacturer (standard keys in hand), the tool ensures the optimization of the flow of logistic information between all partners in the Supply Chain automotive. The SMES are confined yet to the traditional methods of communication given the volume of trade that remains low and also saw the lack of financial and human resources to ensure the introduction of the technology in the enterprise.

Finally, with the advent of cloud computing in the world of technology, the EDI will collect more and more often complement the techniques usually implemented in the projects of dematerialization. In this context, the success of solutions open source and the SaaS via the cloud, requires ensuring the acceptance of new modes of use as well as the transition of data from older software to recent cloud applications. Another interest of the cloud lies in the access to International, it tears down the borders and facilitates the export and responds perfectly to the problems of the automotive industry internationalized. These extraordinary opportunities that appear with the democratization of technologies must push businesses large, medium or small to turn toward the future.

\section{References}

Courtois, A., Pillet, M., \& Martin-Bonnefous, C. (2010). Management of the production (4th ed.). Eyrolles.

CSCMP. (2007). Supply chain management definitions and glossary. Retrieved from https://cscmp.org/supply-chain-management-definitions

Dong, T. T. M. (2015). The knowledge, attitude, and practice of consumers towards food safety issues: A review of Taiwan. International Journal of Research Studies in Management, 4(2), 13-22. http://dx.doi.org/10.5861/ijrsm.2015.976

Fabbe-Costes, N. (2005). Dynamic management of supply chains of virtual companies [La gestion dynamique des supply chains des entreprises virtuelles]. Revue Française de Gestion, 31(156), 151-166. http://dx.doi.org/10.3166/rfg.156.151-166

Frankel, R., Bolumole, Y. A., Eltantawy, R. A., Paulraj, A., \& Gundlach, G. T. (2008). The domain and scope of SCM's foundational disciplines insights and issues to advance research. Journal of Business Logistics, 29(1), 1-30. http://dx.doi.org/10.1002/j.2158-1592.2008.tb00066.x

Jardini, B., Aboulaid, H., \& Elkayl, M. (2016). The information technology and the process reengineering: In the perspective of the planned organizational changes. In Proceedings of ICTO (p. 22). Paris, France.

Jardini, B., Amri, M., \& El Kyal, M. (2016). La gestion de la chaîne logistique par le système JIT (Just in Time) et la technologie EDI (Electronic Data Interchange). Paper presented in the IEEE Conference GOL, FST, Fez, Morocco.

Jardini, B., Amri, M., \& Elkyal, M. (2015). The EDI in the automotive logistic in Morocco: Between technological requirements and classic practices. In Proceedings of the Symposium Logistiqua (pp. 123-129). Marrakech, Morocco: Cadi Ayyad University.

Jardini, B., El Kyal, M., \& Amri, M. (2015). The complexity of electronic data interchange compliance for automotive supply chain. In 2015 IEEE International Conference on Industrial Engineering and Engineering Management (pp. 361-365). Singapore: IEEE. 
Jardini, B., Amri, M., \& El Kyal, M.

http://dx.doi.org/10.1109/IEEM.2015.7385669

Jardini, B., Elkyal, M., \& Amri, M. (2016). Electronic data interchange in the automotive industry in Morocco: Toward the optimization of logistical information flow. European Scientific Journal, 12(3), 186-196.

Mentzer, J., Stank, T., \& Esper, T. (2008). Supply chain management and its relationship to logistics, marketing, production and operations management. Journal of Business Logistics, 29(1), 31-45. http://dx.doi.org/10.1002/j.2158-1592.2008.tb00067.x

Pimor, Y., \& Fender, M. (2008). Production logistics distribution and support [Logistique production distribution soutien] (5th ed.). Dunod.

Vijayasarathy, L. R., \& Tyler, M. L. (1997). Adoption factors and electronic data interchange use: A survey of retail companies. International Journal of Retail \& Distribution Management, 25(9), $286-292$. http://dx.doi.org/10.1108/09590559710185763 